

\section{Aproximações entre os conceitos de imagem, em Relações Públicas, e de imaginário, em Castoriadis}

\author{
Approximations between the \\ concepts of image, in Public \\ Relations, and imaginary, in \\ Castoriadis
}

\section{Valmor Rhoden'}

\section{Valeska Maria Fortes de Oliveira ${ }^{2} \square$ \\ Cláudia Eliza de Campos Nunes ${ }^{3}$}

182 PORTO ALEGRE | v. 22 | n. 38 | 2017| p. 182-189 DOI: http://dx.doi.org/10.15448/1980-3710.2017.2.29385 Sessões do Imaginário

\section{Resumo}

O artigo problematiza a imagem, em Relações Públicas, relacionando-a com as ideias de Castoriadis (1982, $1985,1987,1999)$ focadas no imaginário social. $\mathrm{O}$ texto propõe refletir sobre as aproximações possíveis entre as abordagens. O objetivo é construir uma discussão que instigue os profissionais de Relações Públicas a questionar a importância da concepção de imagem em seu desenvolvimento profissional e acadêmico. A metodologia aplicada é a pesquisa bibliográfica, com releitura e discussão de autores de Relações Públicas, que trazem o conceito de imagem, e de textos de Castoriadis, referentes ao conceito de imaginário. As conclusões apontam que, enquanto Castoriadis estudou o imaginário a partir do indivíduo e das suas instituições, as Relações Públicas aplicam a imagem em sentido mais amplo. Mesmo diversas, as abordagens mostram sinais de complementaridade.

\section{Palavras-chave}

Imagem; relações públicas; imaginário social; Cornélius Castoriadis.

\section{Abstract}

The article problematizes image in Public Relations relating it to the ideas of Castoriadis, which are focused on the social imaginary. The text proposes to reflect on the possible approximations between the approaches. The goal is to build a discussion that urges Public Relations professionals to question the importance of the conception of image in their professional and academic development. The applied methodology is a bibliographical research based on re-reading and discussion of Public Relations authors, which bring the concept of image, and Castoriadis writings, referring to the concept of imaginary. The conclusions point put that that while Castoriadis studied the imaginary from the individual and its institutions, Public Relations apply image in a broader sense. Even diverse, the approaches show signs of complementarity.

\section{Keywords}

Image; public relations; social imaginary; Cornélius Castoriadis. 


\section{Introdução}

Em Relações Públicas, estuda-se a questão da imagem, pois o profissional da área atua como gestor da comunicação institucional e, como tal, trabalha para que os públicos de interesse tenham a melhor imagem possível de marcas e instituições. Esse cuidado traz benefícios em termos de aumento e/ou manutenção das vendas, valorização das organizações, estabelecimento de parcerias e ampliação de mercados. Além disso, propicia o retorno institucional (nem sempre tangível), entre vários outros objetivos organizacionais.

A partir da compreensão dessa perspectiva sobre a operacionalidade da área, propõe-se, neste texto, aproximar os conceitos de imagem, lançando-se mão de autores da área das Relações Públicas, e de imaginário, apresentando-se as reflexões de Cornélius Castoriadis $(1982,1985,1987,1999)$. O referido autor apresenta a noção do simbólico, daquilo que está posto para a sociedade (ou o seu devir), em pesquisas sobre os sujeitos e atuação destes na sociedade e a forma como as estruturas sociais influenciam na experiência de vida. Entende-se que os estudos de Castoriadis podem contribuir para a percepção sobre o trabalho com a imagem em Relações Públicas, possibilitando que os profissionais questionem essa concepção em seu desenvolvimento profissional.

Para trabalhar a problemática proposta, o presente texto faz uma revisão teórica. A partir da apresentação dos conceitos, a discussão apresenta, como finalidade, levantar hipóteses a respeito da aproximação entre os vieses estudados.

\section{Metodologia}

Partindo da questão apresentada inicialmente, este texto se estrutura como uma pesquisa bibliográfica. $\mathrm{Na}$ primeira seção de desenvolvimento, serão abordados os conceitos de imagem na área das Relações Públicas, esclarecendo-se brevemente sobre o surgimento da área no mundo e no Brasil. Na sequência, será a vez de apresentar a perspectiva do autor francês Cornélius Castoriadis, que discute o conceito de imaginário social.

A partir desses dois recortes, o artigo apresenta uma seção de discussão, que propõe uma análise que entrecruza as conceituações. Por fim, o texto traz as considerações finais, baseadas na proposta de argumentação, momento em que são verificadas as aproximações entre as correntes com relação às questões teóricas centrais do trabalho: imagem e imaginário social.

\section{O surgimento das Relações Públicas no mundo e no Brasil}

A versão mais aceita pela literatura da área sobre o surgimento das Relações Públicas no mundo data de 1906, com a trajetória do jornalista Ivy Lee. Naquela época, ele exerceu a função de assessor de imprensa para um grupo de empresários nos Estados Unidos. No Brasil, o marco inicial foi na década seguinte, em 1914 em São Paulo, com a criação de um departamento de Relações Públicas na antiga The Light \& Power Co. Ltda, a concessionária da iluminação pública e do transporte coletivo na cidade. A função foi exercida pelo engenheiro Eduardo Pinheiro Lobo, que, durante 19 anos, assumiu as funções de diretor de Relações Públicas da Light, como a empresa ficou conhecida. O "Dia nacional das Relações Públicas" é comemorado no país em
02 de dezembro, em homenagem ao pioneiro, nascido nesta data.

Ao longo de mais de um século de profissão estabelecida no país, muitas questões influenciaram a atuação dos profissionais e as foram modificando. Nos anos do período de ditadura militar, o trabalho de Relações Públicas era muito atrelado aos governos, e, naquela época, ocorreu a regulamentação da profissão. Tal fato se deu, mais precisamente, em 1967, por meio da Lei no 5.377. Foi na década de 1960, inclusive, que começaram a surgir os primeiros cursos superiores da área no Brasil.

Com a democratização, em meados dos anos 1980, a profissão se ampliou e não ficou mais apenas no campo governamental, expandindo-se para a área empresarial também. As Relações Públicas estiveram muito atreladas ao trabalho de comunicação interna no Brasil, porém, após 1995, com a era a internet, pode-se dizer que a profissão mudou muito. Afinal, as tecnologias transformaram a forma como as pessoas e as empresas se comunicam, e isso se refletiu consideravelmente no trabalho do profissional da área, uma mudança que se tornou ainda mais perceptível a partir dos anos 2000.

Para Grunig, Ferrari e França (2011), Relações Públicas é a área gestora da comunicação. E, quando se fala em gestão da comunicação, isso inclui a imagem corporativa. Lopes (2005, p. 74) comenta a importância que tem a questão da imagem no trabalho comunicacional:

[...] reputação e boa imagem passaram a ser consideradas importantes diferenciais diante da concorrência e, para que uma organização possa obtê-las, 
é preciso um trabalho de longo prazo, fundamentado na construção e na manutenção de bons relacionamentos com seus diversos públicos, o que propicia à atividade de Relações Públicas oportunidade de expandir-se, consolidar-se e assumir um papel relevante como área estratégica no contexto da Comunicação Corporativa.

Para delimitar melhor, na perspectiva das Relações Públicas, é importante compreender que uma organização deve possuir boa imagem e reputação diante de seus públicos, elementos imprescindíveis à obtenção de bons resultados mercadológicos e/ou institucionais.

\section{O conceito de imagem em Relações} Públicas

Imagem vem do latim imagoe, segundo o Dicionário Priberam da Língua Portuguesa, pode ser definida como a "representação de pessoa ou coisa" (Imagem, 2017). Logo, a imagem não é necessariamente a realidade. $\mathrm{E}_{t}$ em muitos casos, não é igual a ela. Um exemplo disso é quando acontece uma crise com uma organização e há falta de comunicação. Esse aspecto pode fazer com que surjam e circulem informações falsas e que vão se espalhando de forma rápida, podendo chegar a milhares de pessoas. Se a empresa não se manifestar em tempo para desmentir os boatos, estes podem prejudicar a imagem da companhia. Pode-se dizer, então, que a imagem representa o modo como percebemos um fato ou uma situação, e não realmente como as coisas são. $\mathrm{A}$ maneira como determinada pessoa enxerga uma questão, a imagem que ela tem de outra pessoa ou de uma entidade, não é, necessariamente, algo real, concreto.
Para Bueno (2005, p. 17), imagem e reputação "constituem-se, portanto, em ativos intangíveis absolutamente fundamentais e conseguir gerenciá-los, avaliá-los ou mensurá-los passa a ser uma questão de sobrevivência" para as organizações. $\mathrm{O}$ autor complementa que a "identidade corporativa pode ser entendida, simplificadamente, como a 'personalidade' da organização e está umbilicalmente associada à sua cultura e ao seu processo global de gestão (filosofia gerencial, competência técnica ou de inovação etc.)" (Bueno, 2005, p. 17)

Ainda, entende-se que a imagem tem dois sentidos: a) símbolo gráfico (significando uma representação visual) e b) conceito (remetendo a uma representação mental). Santaella e Nöth (1999, p. 15) esclarecem essas duas diferentes formas:

O mundo das imagens se divide em dois domínios. O primeiro é o domínio das imagens como representações visuais: desenhos, pinturas, gravuras, fotografia e imagens cinematográficas, televisivas, holo e infográficas pertencem a esse domínio. Imagens, nesse sentido, são objetos materiais, signos que representam o nosso meio ambiente visual. O segundo é o domínio imaterial das imagens da nossa mente. Neste domínio, as imagens aparecem como visões, fantasias, imaginações, esquemas, modelos ou, e em geral, como representações mentais. Ambos os domínios da imagem não existem separados, pois estão inextricavelmente ligados já na sua gênese. Não há imagens como representações visuais que não tenham surgido de imagens na mente daqueles que as produziram do mesmo modo que não há imagens mentais que não tenham alguma origem no mundo secreto dos objetos visuais.
O segundo domínio trazido por Santaella e Nöth (1999) é o conceito de imagem que encontra as definições de imaginário na teoria de Castoriadis. A imagem pública de alguém ou de uma marca ou produto, apesar de ser o resultado da interação de projeções interiores de diversos indivíduos, é um fenômeno construído de maneira individual. Trazendo essa reflexão para o contexto organizacional, Cabrera (1996, p. 25, tradução nossa), afirma que:

No conceito da imagem está implícito o interesse do sujeito em sua criação, sua manutenção e, se for o caso, sua transformação. Mas, de qualquer maneira, a imagem obtida não depende somente da vontade e da ação do sujeito. A pesquisa mostra como a atribuição de uma determinada imagem está baseada em parte em atitudes pouco racionais ${ }^{4}$

Os públicos, sejam internos (funcionários, acionistas e familiares), sejam externos (comunidade, imprensa, consumidores etc.), constroem uma imagem, positiva ou negativa, mediante um processo de elaboração que completa a relação de suas experiências com as informações advindas, oficialmente ou não, de ou sobre uma organização, uma marca ou um produto. Portanto, essa construção não é, necessariamente, condizente com a realidade ou com os objetivos institucionais.

Logo, cabe à área de Relações Públicas o trabalho adequado para que a imagem seja a mais positiva possível. Neves (1998, p. 63) afirma que: "Ter direito à sua própria percepção é muito importante para a democracia, mas dá muito trabalho para os comunicadores". No cenário digital, onde todos os indivíduos são potenciais 
emissores, e não mais apenas receptores/passivos, o processo comunicacional se tornou ainda mais complexo.

Para Kunsch (2003), imagem é um conjunto de significados pelos quais se chega a conhecer um objeto e por meio do qual as pessoas o descrevem, recordam e se relacionam. Ela acrescenta que é também o resultado da interação de crenças, ideias, sentimentos e impressões constituídas pelas pessoas sobre determinado objeto.

Nesse sentido, a imagem corporativa se relaciona com a visão que o público possui a respeito de determinada organização e costuma estar fortemente ligada aos produtos gráficos, à identidade visual, enfim, a toda a comunicação formal que é construída por meio das diversas percepções da comunicação em relação a: publicidade, relações com os públicos e com a imprensa, logotipos, cores, embalagens, enfim, todo o processo comunicacional com o qual se tenha contato.

Uma das fontes a partir das quais as pessoas constroem a imagem são os meios da própria empresa (isto é, a comunicação formal, acima descrita). Por isso, é fundamental que a prática comunicacional seja contínua, e não apenas sazonal ou em momentos de crise. Nesse ínterim, o profissional de Relações Públicas precisa compreender a imagem (como ela se constitui e de que modo trabalhar para que seja favorável), meIhorando os relacionamentos com os diversos públicos de interesse de uma marca ou organização.

E como já escreveu Cahen (1990, p. 57), a imagem é o conceito que as pessoas têm ou formam sobre as coisas e, "querendo ou não, gostem ou não, tudo e todos passam uma imagem, inclusive a respeito de si próprios". Ou seja, a todo o momento, estamos criando, alterando ou mantendo a imagem perante os outros.

\section{O imaginário em Castoriadis}

Castoriadis, ao longo de suas pesquisas, dedicou-se a conhecer o sujeito e a atuação deste na sociedade e a forma como as estruturas sociais influenciam a vida das pessoas. Para ele, o que se conhece e aprende faz parte do imaginário social.

A imagem, nas Relações Públicas, como já foi visto anteriormente, está diretamente ligada ao social, e este, por sua vez, opera naturalmente, em uma via de mão dupla à perspectiva do imaginário, oscilando entre o imaginário radical instituinte e o instituído. Para Castoriadis, portanto, o sujeito é histórico e social e o que mantém a sociedade concisa é a instituição na qual se constituem os componentes funcional e imaginário, que proporcionam uma dimensão reguladora, criada pela imaginação dos indivíduos.

Para tanto, o pesquisador tratou de explorar o imaginário social a partir de dois vieses: o que é instituído pela sociedade (pelo decorrer do processo histórico) e aquele que é instituinte nela (pelo sujeito). O "feito" e o "a ser feito", como se refere Castoriadis (1999). A imaginação e o imaginário estão na raiz do pensamento do autor.

Assim, o imaginário elabora o mundo e as possibilidades de criação de sentido. Ele pertence ao constituinte do humano, onde emerge o mundo do sujeito e o social-histórico. Enquanto criação, o ser não se fecha em uma forma determinada: pelo contrário, está sempre aberto, sempre por-ser (Castoriadis, 1987).

O autor aproxima esse conjunto de ideias como uma instituição ampla, a qual ele denomina de imaginário radical-que éinvenção, que mantém um código de regras, normas sociais, línguas, métodos e valores para o indivíduo, só ou na sociedade, com função reguladora. São os magmas das significações imaginárias sociais. Para Castoriadis (1985, p. 29, grifos no original):

Essa teia de significados é o que eu chamo de magma de significações imaginárias sociais que são levadas e incorporadas na instituição de dada sociedade e que, por assim dizer, a animam. Tais significações imaginárias sociais são, por exemplo: espíritos, deuses, Deus; pólis, cidadãos, nação, estado, partido; bens, dinheiro, capital, taxas de juros; tabu, virtude, pecado etc. Mas também homem/ mulher/criança.

O imaginário instituído é composto por tudo o que é criado pela sociedade, é inércia. O imaginário acontece por contágio, por identificação, pelo reconhecimento de si no outro, por integração a uma ideia, pela ideia de ver o mundo de maneira compartilhada. Enfim,

O laço social serve de cimento à vida em sociedade. Porém só se atualiza pela força de valores partilhados, de imagens reverenciadas em conjunto e de sentimentos e afetos intensificados pela comunhão. Não há laço social sem imaginário (Silva, 2003, p. 21)

O imaginário instituinte vai se criando à medida que a sociedade se transforma, como autocriação, como capacidade de instituir-se, fonte de sua própria alteridade. A imaginação é a pura realidade psíquica que se apresenta em forma de representação. Essa função imaginária, segundo Castoriadis, é humana e permite que sejamos simbólicos. Para Riffel (2017 p. 52): 
A imaginação é, assim, algo que a razão não é capaz de definir exatamente, mas que compõe toda a vida humana e estabelece todas as nossas possibilidades de relação. Cada ser, sujeito, individual, é capaz de olhar-se no espelho e visualizar no real uma imagem, que foi construída imaginariamente por ele e que ao se ver representa o 'real'; [...] e (assim) originam-se as muitas formas de convívio social. A própria possibilidade de fantasiar relações, imaginar o que o outro está pensando ao meu respeito, cons truir imaginariamente as expectativas que o outro tem de mim e o que eu tenho a meu respeito ainda estabelecem-se originalmente na imaginação.

O imaginário social proposto por Castoriadis (1982) apresenta o simbólico do que está posto para a sociedade e dá margem ao inusitado. Segundo o autor, ao entrar em contato com as significações imaginárias de um grupo, é possível compreender as ideias que configuram a realidade e também o movimento que acontece entre o que existe e um vir a ser. E Córdova (1994, p. 27) ainda frisa que:

O imaginário, portanto, no sentido utilizado po Castoriadis, é algo que introduz o novo, constitu o inédito, a gênese ontológica, a verdadeira temporalidade, a posição de novos sistemas de significados e de significantes, presentifica o sentido. $\mathrm{E}$ passa a ser o imaginário radical o verdadeiro motor da sociedade e da história.

Sendo assim, as ações, as representações simbóli- cas, as imagens criadas pelos indivíduos no mundo são parte do imaginário que as envolvem em detrimento de seus atos. Elas vêm carregadas de sentimentos, imagens derivativas, lembranças, experiências de vida, crenças individuais e grupais concretizadas por modos de ver, ser, agir e estar no mundo.

Na esteira da imaginação, há que se pensar na criação, pois ambas fazem parte da mesma teia a ser tecida pelo humano no campo do sensível. Duarte Júnior (2012) aponta para a educação do sujeito como algo pautado pela dimensão imaginativa, emotiva e sensível. A imaginação é a capacidade fundamental do humano.

Assim, projetamos o nosso devir. O imaginário envolve o espaço antropológico da imagem, vai do inconsciente ao consciente; do sonho e da fantasia ao pensado; do irracional ao racional, não como reprodução, mas como criação. Dessa forma, temos o universo das imagens simbólicas que permeiam a sociedade.

Para Castoriadis (1982), o imaginário é fruto da construção da realidade e o real é acionado pela eficácia do imaginário, das construções. $O$ imaginário é sensibilidade, é sentimento, é afetivo, é, ao mesmo tempo, impalpável e real. Opera pelo campo da interação, é um momento de vibração, de compartilhamento.

A imagem, na dimensão do imaginário, é a representação que questiona de que modo pode-se provocar a capacidade de imaginar e criar, que opera como possibilidade de constituição de subjetividade e de mundo, de ver o todo simbolicamente. É o dualismo entre real e imaginação, é sensação, percepção, fantasia, sonho, fabulação, arte, atividade imaginativa. $\mathrm{E}_{\text {, }}$ para Castoriadis (1982), o imaginário é esse fundamento em realidade criadora.
Logo, é a via imaginal de percepção do mundo e de nós mesmos (o reino das imagens) que nos cria. E ela tem força, é dinâmica. Consequentemente, por meio da pedagogia da imagem, pensa-se o mundo por intermédio dos símbolos e do imaginário individual e coletivo. Segundo Silva (2003, p.73), para ser pesquisador do imaginário, é preciso demonstrar:

[...] mais do que isso ou aquilo, deve mostrar, dar a ver, fazer vir, desentranhar, fazer emergir, revelar, descobrir, desvendar, expor à luz. Não Ihe basta conhecer o poder (institucional, explícito), deve perceber o fluxo da potência (subterrânea). Se não pode provar o que aconteceu no passado nem prever o futuro, cabe-lhe narrar bem o presente. Mescla de antropólogo, de fotógrafo, de repórter, de cronista e de romancista, necessita captar e narrar a fluência, o extraordinário e a complexidade do vivido.

Logo, o processo envolve construir imagens do ontem, do hoje e do amanhã, relações, sonhos, percepções do outro que vemos e do outro que nos vê, que se aproxima e se afasta. Da representação, do simbólico, do instituído e do instituinte: tudo isso integra o devir do imaginário.

Por que uma imagem toca tanto? Porque é comunicação, por ser da potência do movimento que ela tem de contar uma história sem sinais verbais, de influenciar uma vida, de modificar uma escolha de representar, de nos levar ao diferente. A possibilidade do registro de um lugar. De sentido, de pertencimento, de memória, de histórias. 
Tudo acontece pelo espaço do imaginário instituído, pelo que está posto e possibilita reflexão, questionamento, imaginação e autonomia. Tudo tem um princípio, constrói uma história, uma referência e vem de um exercício de reflexão. $E$, assim, as experiências tornam-se instituintes no devir do complexo do seu desenvolvimento.

O imaginário social não é a criação de imagens na sociedade, não é o fato de que se pintem os muros das cidades. Uma criação fundamental do imaginário social, os deuses ou as regras de comportamento, não é nem visível nem mesmo audível, é significável (Castoriadis, 1999, p. 102, grifos no original).

O imaginário demanda saber o que significam as imagens, o que elas fazem, o modo como elas se comunicam, por meio de signos e símbolos, o tipo de poder que elas têm, o modo como afetam as emoções e a característica de afeto que elas proporcionam nas perspectivas culturais, de linguagem e estética.

A imagem incita a questão interpretativa e retórica e também leva à reflexão sobre o desejo do consumir, da subjetivação, da personificação do que aparentemente está inanimado, como um experimento de pensar. A imagem opera no imaginário ao se comunicar com quem a observa de maneira figurativa ou silenciosa. Imagem é conexão imaginária. Não é superfície, é base, é face. É mediação.

Observando pela perspectiva do imaginário, a imagem é a cópia mental de algo, a relação do real com o conhecimento. É o que nos move a pensar, a criar.
Uma tentativa de apresentar as aproximações entre as visões

Ao se unir os temas, que são estudados em áreas diferentes, mas, a priori, podem ter semelhanças, é possível desenvolver uma análise sobre essa linha de raciocínio que ainda apresenta campo para discussão, numa perspectiva diversificada: buscar o conceito de imagem preconizado na área das Relações Públicas e analisá-lo sob a visão do imaginário em Castoriadis.

As conceituações, em seu olhar amplo, podem ser vistas como complementares. O olhar, no campo das Relações Públicas, sobre a questão da imagem é mais holístico, ou seja, é visto de uma perspectiva ampla, da opinião pública, para amparar planejamentos e ações de comunicação. Dos autores apresentados, os conceitos de Kunsch (2003) e Santaella e Nöth (1999) são os que mais se aproximam da visão de Castoriadis.

Já Castoriadis, apesar de ver a repercussão no campo social, evidencia, como preocupação essencial, a forma como o imaginário se constitui no ser humano, intrinsecamente. Por isso, a visão desse pesquisador pode ser entendida como uma base para os estudos de imagem em Relações Públicas: afinal, propõe pensar sobre onde e como ela se cria, na essência, no indivíduo, e de que modo se amplia na sociedade, posteriormente. Nesse ponto, as ideias e os conceitos convergem. A imagem por ser ampla, holística, é inerente ao processo de criação e imaginação humana.

Cada pessoa tem a liberdade de perceber as coisas do jeito que deseja. Existem diversas formas de enxergar a mesma coisa. As percepções imaginárias tratam de sentimentos, de consciência, de vontades, de relações sociais. Imagem é transformação, é elemento que constitui a realidade social. É um tipo de linguagem, mas é imagem, não só linguagem, é imaginação e pode estar em constante transformação e alteração. Para dar um exemplo, o que alguém ama hoje, em termos de produto, pode odiar amanhã, dependendo do que houve de influências que chegaram até determinada pessoa e a fizeram mudar de sentimento e, consequentemente, de comportamento. Ou seja, a imagem foi transformada. É por isso que se afirma, em Relações Públicas, que, quanto mais solidificada estiver a imagem na mente das pessoas, mais difícil é que ela seja alterada. Afinal, a representação estará menos suscetível a situações corriqueiras. Portanto, a manutenção do trabalho contínuo é fundamental.

Nesse sentido, é possível afirmar que a imagem é uma representação que surge na nossa mente, como síntese de uma ou várias sensações e percepções, a partir do nosso olhar e de nossa perspectiva e visão de mundo. Já o imaginário é a coletividade, é onde os indivíduos estão inseridos, o que caracteriza um grupo.

Uma diferença observada por esta pesquisa é o fato de que, enquanto Castoriadis tem o interesse na perspectiva do ser humano a partir da potência criadora, em Relações Públicas, isto é visto e estudado numa perspectiva organizacional/institucional. Neste ponto, há um distanciamento de foco.

Em Relações Públicas, quando formamos uma imagem positiva de pessoas, produtos, marcas, instituições, entre outros, isso é fator de vantagem competitiva e de mercado. Logo, todo o esforço comunicacional e de marketing para que algo seja positivo na mente das pessoas é essencial, pois ajuda a alavancar os objetivos estabelecidos.

Já na reflexão de Castoriadis, a razão não define exatamente a imaginação que se tem das coisas, mas, mes- 
mo assim, esta compõe a vida das pessoas. Imagina-se sobre imagens propriamente ditas e sobre imagens de pessoas, imagens construídas imaginariamente em meio ao convívio social puro e simples, e não como um processo cultural global de gestão. Não como algo a se gerenciar, avaliar ou mensurar, e sim como potência de compartilhar e criar o novo, o inusitado, o ainda intangível.

\section{Considerações finais}

Trazer o entendimento sobre imagem e imaginário foi o eixo central deste trabalho. Conhecer as ideias de Castoriadis, encontrar definições e entender o pensamento desse filósofo, psicanalista, economista e sociólogo, que nos impele a reflexões sobre o ser humano, a individualidade, o mundo e a sociedade em que vivemos, por meio de pesquisas nas áreas de administração, filosofia, economia, educação, direito, entre outras, foi um exercício praticado neste artigo. E, somado a isso, buscou-se entrelaçar a perspectiva do pesquisador com as visões de autores da área das Relações Públicas.

Os principais conceitos de Castoriadis, imaginário, sócio-histórico e a criação como característica de fundação no ser humano, apontam a íntima relação entre o tema aqui desenvolvido com a área de Relações Públicas. O imaginário faz parte e traz interesse dos mais diferentes campos e provoca muitas potências e reflexões, pois trata do criar, das representações individuais e coletivas em suas relações sociais. Ele compreende o desenvolvimento da autonomia da imagem em relação ao seu conteúdo, ao conhecimento de novos padrões a serem criados, à construção de alternativas, à transformação da sociedade.

A área de Relações Públicas trabalha com os públicos de interesse para que a imagem das organizações/ marcas sejam as melhores possíveis, utilizando, para tal, todo o arcabouço de estratégias comunicacionais, incluindo a comunicação interna, institucional e mercadológica e, nelas todas, as ferramentas do cenário digital. A partir desses cuidados, é possível que os objetivos sejam alcançados, tanto os internos quanto os comerciais/de mercado ou institucionais.

A imagem, em termos de Relações Públicas, pode ser trabalhada por meio de ferramentas dirigidas ou de massa, porém, ela é formada, por cada pessoa. Isso mostra a complexidade da temática ora discutida e a proximidade do trabalho da área com a visão de Castoriadis.

Tal aproximação entre as perspectivas descritas mostra que Castoriadis se preocupa com o processo de criação do pensamento, ou seja, como ocorre a formulação do imaginário, que, em Relações Públicas, é a base do que é a imagem construída.

Na perspectiva da área gestora da comunicação, a imagem é formada pelos públicos, da sociedade ou parte dela, é resultado do que as pessoas pensam quanti-qualitativamente, dependendo dos objetivos estruturados. A imagem pesquisada e trabalhada pelas Relações Públicas parte do eixo individual (apresentado por (astoriadis) e é ampliada para o campo social.

\section{Referências}

BUENO, W. C. A personalização dos contatos com a mídia e a construção da imagem das organizações. Revista Organicom, São Paulo, n. 2, v. 2, p. 10-27, 2005.

CABRERA, J. A. Las relaciones públicas en la empresa. Madrid: Acento Editorial, 1996.

CAHEN, R. Tudo que seus gurus não lhe contaram sobre comunicação empresarial: a imagem como patrimônio da empresa e ferramenta de marketing. São Paulo: Best Seller, 1990.

CASTORIADIS, C. A instituição imaginária da sociedade. Tradução Guy Reynaud. 5. ed. Rio de Janeiro: Paz e Terra, 1982.

Os destinos do totalitarismo e outros escritos. Tradução Élvio Funck e Zilá Bernd. Porto Alegre: L\&PM, 1985.

As encruzilhadas do labirinto Il: os domínios do homem. 1. ed. Rio de Janeiro: Paz e Terra, 1987.

As encruzilhadas do labirinto V: feito e a ser feito. Tradução Lílian do Valle. Rio de Janeiro: DP\&A, 1999.

CÓRDOVA, R. A. Imaginário social e educação: criação e autonomia. Em Aberto, Brasília, ano 14, n. 61, p. 24-44, jan./mar. 1994

DUARTE JUNIOR, J. F. Por que arte-educação? Campinas: Papirus, 2012.

GRUNIG, J. E.; FERRARI, M. A.; FRANÇA, F. Relações Públicas: teoria, contexto e relacionamentos. 2. ed. São Caetano do Sul: Difusão Editora, 2011.

IMAGEM. In: Dicionário Priberam da Língua Portuguesa. Disponível em: <https://www.priberam.pt/ dlpo/imagem> Acesso em: 16 nov. 2017. 
LOPES, V. S. C. O relações-públicas como gestor da imagem e a importância da mensuração dos resultados em comunicação corporativa. Revista Organicom, São Paulo, n. 2, v. 2, p. 70-95, 2005.

\section{KUNSCH, M. M. K. Planejamento de relações públicas} na comunicação integrada. São Paulo: Summus, 2003.

NEVES, R. C. Imagem empresarial. Rio de Janeiro: Mauad, 1998.

RIFFEL, A. C. Autonomia e imaginário na educação: o pensamento de Castoriadis e a relação com o tema da criação. 2017. 110 p. Dissertação (Mestrado em Educação nas Ciências) - Universidade Regional do Noroeste do Estado do Rio Grande do Sul, ljuí, 2017.

SANTAELLA, L.; NÖTH, W. Imagem: cognição, semiótica, mídia. 2. ed. São Paulo: lluminuras, 1999.

SILVA, J. M. As tecnologias do imaginário. Porto Alegre: Sulina, 2003.

\section{Notas}

1 Doutor em Comunicação Social pela Pontifícia Universidade Católica do Rio Grande do Sul (2013). Mestre em Extensão Rural pela Universidade Federal de Santa Maria (2001). Pós-doutor em Educação pela Universidade Federal de Santa Maria (2018). Professor Adjunto do curso de Relações Públicas da UNIPAMPA - campus São Borja (Universidade Federal do Pampa, Curso de Relações Públicas da Unipampa. Rua Ver. Alberto Benevenuto, 3.200. Passo. 97670-000 - São Borja, RS Brasil).Email:valmor@unipampa.edu.br.
2 Doutora em Educação pela Universidade Federal do Rio Grande do Sul (1995). Mestre em Educação pela Universidade Federal de Santa Maria (1990). Pós-doutora em Ciências da Educação pela Universidade de Buenos Aires (2007). Professora Titular do Departamento de Fundamentos da Educação do Centro de Educação da Universidade Federal de Santa Maria (Universidade Federal de Santa Maria, Centro de Educação, Departamento de Fundamentos da Educação. Centro de Educação - Campus Universitário - Sala 3282. Camobi. 97119-900 - Santa Maria, RS) Email:vfortesdeoliveira@gmail.com.

3 Mestre em Educação pela Universidade de Santa Cruz do Sul (2010). Especialista em Educação Infantil pela Universidade Franciscana (2004). Graduada em Pedagogia pela Universidade Federal de Santa Maria (1988). Educadora Infantil na Escola Municipal de Ensino Fundamental Padre Nóbrega, e coordenadora do Laboratório de Informática da EMEF Francisca Weinmann na Rede Municipal de Ensino de Santa Maria (Prefeitura Municipal de Santa Maria, Secretaria da Educação. Rua Venâncio Aires. Centro. 97090000 - Santa Maria, RS) Email: claucn06@hotmail.com.

4 No original: “En el concpto de imagen está implícito el interés del sujeto en su creación, su mantenimiento y, en su caso, su transformación. Pero, de todos modos, la imagem obtenida no depende estrictamente de la voluntad y de la acción del sujeto, no enteamente; la investigación demuestra cómo la atribuición de una determinada imagen está basada en parte en actitudes poco racionales". 